\title{
DEFLATED CONCEPTS: A REPLY TO STAINTON
}

\author{
ALEX BARBeR \\ Department of Philosophy \\ University of Bristol
}

\section{Introduction}

In "The Deflation of Belief Contents" (this journal, December 1996), Robert Stainton attempts to undermine a deflationary approach to concepts. His broader target is the deflationary approach to belief in general, incorporating theories which aim to deflate the state of believing as well as theories which aim to deflate the content of beliefs (concepts and/or propositions). Yet his criticisms are very much focused on the pleonastic theory of concepts - a theory which attempts to deflate concept discourse. ${ }^{l}$ In what follows, I attempt to defuse his two main objections to this theory. The first of these concerns the treatment of concept mastery, and it necessitates an alteration to the original theory. It is possible to view mastery of a concept as understanding of $a$ term that expresses the concept in some language; and viewing it in this way does not threaten

1 This is the theory presented in "The Pleonasticity of Talk About Concepts", Barber (forthcoming). Though the present discussion will not presuppose acquaintance with that article, only there do I present the broader case for the pleonastic theory. 
the deflationary character of the pleonastic theory, given a proper construal of understanding. Though he anticipates this alteration, Stainton deals with it inadequately. As to the second objection, Stainton has not shown that appeals to deeper-than-surface syntactic constituency, of the kind familiar in contemporary linguistics, must engender more robust an interpretation of concept discourse than is compatible with the pleonastic theory.

Responding to Stainton's criticisms requires developing the pleonastic theory beyond its original form, so a very brief recapitulation of the earlier version is in order. The objections and my response to them relate largely to the following two clauses of the theory: ${ }^{2}$

Original clause for concept possession

Someone possesses a particular concept iff $_{d e f n}$ they have at least one attitude towards some proposition involving that concept.

Original clause for concept involvement

The concept expressed by term $e$ is involved in the proposition expressed by sentence $S$ iff $\operatorname{defn}_{n} e$ is a syntactic constituent of $S$.

These two clauses combine to give the following general result:

$A$ possesses the concept expressed by $e$ iff there is at least one true substitution instance (replacing $S$ with a sentence having $e$ as a syntactic constituent, and $\phi$ with a propositional attitude verb) of the following schema:

$A \phi$ s that $S$

of which the following is an instance:

2 For the third clause, which states what concepts are, see Barber (forthcoming), section four. The two clauses below correspond to Stainton's (5) and (6), p. 66. The clause for mastery, not explicit as a clause in the original article, is made so below.

84 
Dorothy possesses the concept cat iff:

Dorothy believes that there is a cat in the fridge or Dorothy hopes that there is a cat in the fridge or Dorothy believes that cats are Martian robots or ...etc...

Though few would quarrel with the biconditionals in the two clauses when not regarded as constitutive, the force of the pleonastic theory comes from treating them as definitional of concept possession and concept involvement. One of the more significant consequences of doing so is that lacks-the-concept inferences are undermined. Concept-talk is derivative of the attribution of propositional attitudes, and so cannot deliver independent defeating conditions on such attributions (Stainton 1996, p. 70; Barber (forthcoming), section one). A conjecture affiliated to the theory is that concepts, concept possession, and concept involvement are linguistic epiphenomena, phantoms generated by the following kind of transformations: 'Marie believes all London buses to be red' can be pleonastically re-expressed as: 'Marie possesses the concept red and believes all London buses to fall under it'.

\section{Stainton's first objection: concept mastery}

Stainton's first objection to the pleonastic theory concerns the treatment of concept mastery (pp. 71-75). He argues that the relatively weak conditions on concept possession require a distinction to be made between possessing a concept and having mastery of it. This result - though not the example he uses to make it - is one I had already addressed in the original article. ${ }^{3}$ There, I proposed that

3 Under Objection and Reply VI. I am wary of the example on p. 71. The sentence is arguably shorthand for 'John is unsure whether the expression "podiatrist" refers to medical doctors'. If so, then even 
'mastery', in contradistinction to 'possession', be defined as follows:

Original clause for concept mastery

$A$ has mastered the concept expressed by term $e \operatorname{iff}_{d e f n} A$ understands $e$,

where to understand term $e$ is to know the relevant clause for $e$ in a semantic theory. But Stainton takes exception - with good cause it turns out - to this simple analysis of mastery.

The first of Stainton's two concerns about the analysis of mastery in terms of understanding is that it will "founder on cross linguistic cases" (p. 74), cases where different languages express the same concept. Here is a reconstruction of his argument, based on the example of Maria, an extremely monolingual Spanish-speaking computer expert:

Premise One Maria has mastered the concept expressed by 'computadora'

Premise Two 'Computadora' expresses the same concept as is expressed by 'computer'

Subconclusion Maria has mastered the concept expressed by 'computer' ( $P 1, P 2$, by sortal identity)

Premise Three Maria does not understand the word 'computer'

Conclusion Mastery of the concept expressed by 'computer' does not always require understanding the word 'computer' (P3, subconclusion)

This argument, I concede, refutes the simple analysis

after granting that John has not mastered the concept podiatrist (perhaps because he does not understand the relevant expression), John may well have no attitude towards a proposition involving the concept podiatrist. Although it is mentioned, the term "podiatrist" is not used within the embedded sentence (i.e. within "The expression "podiatrist" refers to medical doctors'). So John would not possess the concept. 
of mastery above. That analysis can be slightly altered, however, to give:

Revised clause for concept mastery

$A$ has mastered the concept expressed by $e$ (in $L$ or by $e^{*}$ in $L^{*}$, by $e^{* *}$ in $L^{* *}$, etc.) iff defn $A$ understands $e$ (or $e^{*}$, or $e^{* *}$, etc.).

Both the definiens and the definiendum have had to be adjusted to accommodate the fact, overlooked prior to Stainton's drawing our attention to it, that a concept can be expressed by different terms in different languages. This new definition is composed out of numerous special cases:

$A$ has mastered the concept expressed by [some expression] in [some language] if $A$ understands [that expression].

These special cases amount to individually sufficient but, when taken all together, disjunctively necessary conditions for mastery of the relevant concept. When the special case is the home language, we get the original definition; the mistake was to assume that any single case, even the home language case, could by itself amount to a necessary condition on mastery. ${ }^{4}$

Stainton appears to anticipate this modest adjustment when he writes:

It's bizarre to suppose that this sentence [i.e. 'Maria, a monolingual speaker of Spanish, has mastered the concept PODIATRIST'] is really about Maria's relationship to some Spanish word - for a speaker of [this sentence] may have no idea what Spanish word encodes PODIATRIST (p. 74).

But this passage commits a non sequitur. Why should a responsible asserter of the sentence have to know which

4 I shall say at the end of this section what it is for a term to express a concept, and what it is for two terms in different languages to express the same concept. 
Spanish word does the encoding or expressing? All that is required for the sentence to be true, on the revised view of mastery, is that there be some such word and that Maria understands it. And a monolingual speaker of the English sentence could obtain this information through, for instance, reliable testimony from a bilingual mutual acquaintance.

Incidentally, parallel parenthetical addenda to the clause for concept involvement are also required, for similar reasons:

Revised clause for concept involvement

The concept expressed by $e$ (in $L$ or by $e^{*}$ in $L^{*}$, by $e^{* *}$ in $L^{* *}, e t c$.) is involved in the proposition expressed by $S$ (in $L$ or by $S^{*}$ in $L^{*}$, by $S^{* *}$ in $L^{* *}$, etc.) iff defn $e$ (or $e^{*}$, or $e^{* *}$, etc.) is a syntactic constituent of $S$ (or $S^{*}$, or $S^{* *}$, etc., respectively).

As for mastery, only after acknowledging the existence of multiple languages can the definition for involvement be made properly comprehensive. And as for mastery, the changes are at worst cumbersome.

Stainton's second concern with the analysis of mastery in terms of understanding is that it turns concepts into meanings, when to accept meanings into one's ontology undermines the deflationary policy ostensibly driving the pleonastic theory. "[C]oncepts essentially become Fregean senses, or Russellian meaning-relata, and hence are not 'deflated" " (p. 75). Responding to this charge would ideally include a criterion for when a theory is or is not "truly deflationary" (p. 74) of its discourse domain. Rather than enter into an open-ended discussion of this interesting methodological issue, I shall attempt to reply to Stainton's specific charge more directly. Doing so requires an assumption in lieu of a fully worked out criterion for "true" deflation. The assumption is this: the inflation charge would be rebutted 
by an adequate account of understanding which required no objectionable reification of meanings.

We can regard understanding as knowledge without hypostasizing meanings. That is, we do not have to regard understanding as knowledge of "the meaning" of a particular word, except as a turn of phrase. Instead, we can say that to understand an expression, $e$, is to know the relevant clause for $e$ in a semantic theory. For example, understanding the word 'computadora' involves knowing inter alia that:

For any $x$, sem.val. ( $x$, 'computadora') iff $x$ is a computer.

(Incidentally, knowing this does not require understanding the word 'computer', any more than does knowing that computers are revolutionising the world of work; monolingual Maria can still count as someone who understands 'computadora'.) Supposing that this $i s$ what understanding is, can we find any objectionable ontological commitment? What is "the meaning" of an expression on this account, if we force ourselves into identifying such a thing? Perhaps it is its semantic value or Bedeutung -in this case, a computer or the set of all computers. But if so, there is nothing to worry about. One can be deflationary about concepts without being deflationary about computers (or the set of all computers, etc.). To the extent that particular Bedeutungen are theoretically or ontologically questionable, they will be so for everyone, not just for a supporter of the pleonastic theory of concepts. Seeking elsewhere for "the meaning" of expressions on the present construal of understanding, we could claim that the meaning of 'computadora' is that it (the expression) has such and such a Bedeutung. The sole achievement of adopting this slightly awkward turn of phrase would be to effect a reconciliation between, on the one hand, a literal reading of the dictum, "understanding a phrase is knowing its meaning" and, on 
the other, the construal of understanding as knowledge of a semantic clause. Even if it does achieve this reconciliation, we should beware of supposing the apparent reification of meanings to be anything other than the result of this way of talking. 5

To summarise, treating understanding as knowledge of meaning does not undermine a deflationary attitude towards concepts. If meanings are Bedeutungen there is no incompatibility between their existence and the deflationary attitude towards about concepts, still less a reason to think meanings are concepts; whereas if meanings are facts that a term has a particular Bedeutung, it is possible to regard the objecthood of meanings as a linguistic epiphenomenon, which would accord with the deflationary spirit of the pleonastic theory.

A side issue must be isolated from the foregoing discussion, particularly in view of Stainton's reference to Fregean senses. I am making liberal use of the - mildly controversial - premise that understanding a language amounts to knowing the clauses of a compositional semantic theory for that language. But there is a famous difficulty facing anyone who supposes compositional semantic theories can be given: the difficulty associated with opaque contexts. One way - effectively Frege's way - of dealing with this problem involves distinguishing between a term's having a particular Bedeutung, and its being associated with a particular Sinn, or sense, or meaning, or concept (according to whose translation of Frege's work one adopts). ${ }^{6}$ This

5 The basic point of this paragraph is strongly influenced by section three of John McDowell (1977).

6 Frege (1892). Incidentally, it is unhelpful to translate 'Sinn' as 'concept', since 'concept' is normally reserved for "Begriff", and Sinnen and Begriffen are certainly distinct for Frege. Begriffen are functions from objects to truth-values, and are the (regular) semantic values of predicate expressions only (Frege 1891). Sinnen can be 
highly specialised usage of 'sense', 'meaning', or 'concept' is called for only if no other treatment of the problem is available. Though inclined to think that such a way is available, ${ }^{7}$ my main purpose here is to point out the localised character of this problem and of the associated usages of 'sense', 'meaning', or 'concept'. It would, in particular, be unfair to argue as follows: we are bound to introduce an inflated understanding of 'sense' or 'concept' in solving the opacity problem, since the sense or concept associated with a term will be its semantic value in opaque contexts. If the semantic value of a term in an opaque context is nothing but its regular semantic value, as 'innocent' semanticists following Davidson (1984) have held, then there need be nothing inflationary about a term's having a sense, in this usage of 'sense'.

I promised in a footnote to say what it is for an expression to "express" a concept, since fairly heavy use has been made of this locution. ${ }^{8}$ Let $e$ be an expression, and let some particular substitution instance (replacing ' $C$ ') of 'For all $x$, sem.val. $(x, e)$ iff $x$ is a $C^{\prime}$ be a clause in an adequate semantic theory for the object language from which $e$ is drawn. Then we can say, pleonastically, that $e$ expresses the concept $C$ (substituting once again for ' $C$ '). Examples make this easier to see: the concept cat is expressed by 'chat', since for all $x$, sem.val. ( $x$, 'chat') iff $x$ is a cat. A parallel account could be offered of the expression of propositions

associated with members of no matter which category of expression; moreover, Sinnen are not (ordinarily) the semantic values of expressions, not even of predicate expressions.

7 Barber (forthcoming), Reply to Objection IV.

8 The aim is to develop a clause for every type of occurrence of the term 'concept'. We have clauses for 'possesses the concept', 'involves the concept', 'concept (simpliciter)', and now 'has mastered the concept'. 'Expresses the concept' generates the need for yet another clause. 
by sentences by looking to the T-sentences derivable from the semantic clauses. As a corollary, two expressions (such as 'computadora' and 'computer') express the same concept - and so translate one another - if substituting the name of the second for the name of the first in the left-hand side of a semantic clause of the first's object language would yield a semantic clause of the second's object language.

A fairly heavy load is being borne here by the compositional semantic theory assumed to be known by the people we can pleonastically describe as having mastery of particular concepts. This is not something to play down. Indeed, an original motivation for the pleonastic theory was that it can be used to block a lacks-the-concept objection to the claim that typical language-users could plausibly be said to know a semantic theory (Stainton, p. 70; Barber, endnote three). But this still leaves open the question of how we come to settle on the appropriate clauses for such a theory. One requirement of the pleonastic approach to concepts, indeed one of its recommendations, is that the wrong way to go is in search of concepts - or reified meanings - to hook up with words in forming the clauses (unless, as ever, this is merely a pleonastic description of some more helpfully characterisable procedure).

3. Stainton's second objection: deeper-than-surface syntactic constituency

Stated broadly, Stainton's second main objection (pp. 7579 ) is this. In the clause of the pleonastic theory dealing with concept involvement, appeal is made to the notion of syntactic constituency. But identification of syntactic constituency really proceeds though the identification of concepts, so the pleonastic theory has placed the cart before the cart-horse. 
More specifically, Stainton argues as follows. Appealing to syntactic constituency will allow us to capture concept involvement only if we look to constituency at deeperthan-surface levels of representation. This is because for concepts such as build up, the term expressing the concept (i.e. 'build up' is not always a surface-level constituent (p. 78). One problematic consequence is that certain easyto-apply mechanical tests available to detect constituency at the surface level of representation - susceptibility to preposing, postposing, and fragmentation- have no parallel at deeper-than-surface levels (pp. 76-78). This is not in itself a knock-down objection, for it means merely that detection of the desired kind of constituency will be that much more difficult. Lacking a simple litmus-test, we are forced back onto overall theoretical cogency as the indicator of constituency.

If absence of any simple detection-test is not the main objection, then perhaps the problem is one of how to say what constituency at the deeper-than-surface level is, without lapsing into talk of concepts — and so into circularity. But here too the challenge is easily met, since constituency at this level is defined just as it is for the surface level: an item is a constituent at a level of representation $R$ iff $_{d e f n}$ it is dominated by a single node at $R$ (p. 76). And so the concept expressed by $e$ is involved in the proposition expressed by $S$ iff $e$ is dominated by a single node in some particular deeper-than-surface representation of $S$.

Stainton's real challenge (as I interpret it) concerns the theoretical role of structure and constituency at this level. According to a standard picture in linguistics, there are two interfaces between the language module and other dimensions of the human mind: the PF-interface and the LF-interface. These interfaces match the disciplinary boundaries between syntax and either phonology (for the PF-interface) or the study of the "conceptual-intentional 
system" (for the LF-interface). The whole point - the theoretical role - of a syntactic theory's surface level representations requires it to mesh with phonological theory. At the other interface, it would not do if our syntactic theory failed to provide representations which meshed successfully with the best theory of whatever lies beyond the LFinterface. The main theoretical role of structure at LF is to facilitate this meshing, just as the main theoretical role of an attribution of structure at $\mathrm{PF}$ is to make meshing with the theory of our perceptual-and motor-apparatus possible.

Here, then, is what I take Stainton's challenge to be: what lies beyond the LF-interface is something irremediably conceptual; so (from the perspective which can encompass the broader theoretical-role) an item will only be correctly suited to being a constituent at LF if it can be associated with a single concept. In his own words:

Whether an element is a D-structure constituent depends, in essence, upon whether it encodes a concept! If this is right, then the order of explanation would be precisely the reverse of that just offered: [...] 'built up' [is a] deeper-than-surface constituent [of a given sentence] because [it is] involved in the content which [this] sentence expresses (p. 78).

Having clarified my interpretation of the objection, I turn to responding to it.

What this objection needs, if it is to be successful, is a reason for thinking that the stuff beyond the LF-interface $i s$ conceptually structured in any robust sense. Basically, the LF-interface is the psychological link between language and general thought, and so what lies beyond the interface is general thought. It would be prejudicial to the pleonastic theory if general thought were simply assumed to be conceptually structured in some robust sense. If Noam Chomsky and others have occasionally referred to the interface as one between the language module and the "conceptual- 
intentional system', we need a reason to think of this as more than a façon de parler, of no crucial theoretical import, easily replaceable by 'intentional system'.

In the context of a paper dealing with the possible limitations of rational scientific enquiry, Chomsky (1995) is candid about our state of ignorance with respect to such "important and obscure questions [... as how...] lexical resources relate to belief systems" (p. 23). And earlier in the same article he writes:

The articulatory-perceptual aspects [of languages' interfacing] have been intensively studied, but there matters are still poorly understood. At the conceptual-intentional interface the problems are even more obscure, and may well fall beyond human naturalistic inquiry in crucial respects (p. 20).

In the face of such comments, passages elsewhere which claim that the interface between language and the "belief systems" consist of associations between concepts and sounds (p. 15) can plausibly be regarded as loose, or at best speculative.

Stainton himself quotes passages from Haegeman and Chomsky which, he implies, manifest a thoroughgoing commitment to the conceptually imbued character of the stuff beyond the interface - a commitment that cannot be dismissed as a mere façon de parler:

$[\mathrm{B}] \mathrm{y}$ definition, D-structure "encodes the predicate-argument relations and the thematic properties of the sentence" (Haegeman 1991, p. 273); it expresses "semantically relevant grammatical functions and relations" (Chomsky 1986b). Thus whether an element is a D-structure constituent depends, in essence, upon whether it encodes a concept! (p. 78) But the conclusion drawn reads more into the passages quoted than is warranted. These passages are saying only that the structure of the representation of the sentence is relevant to that sentence's semantic interpretation. Claiming that a 
structural description of a sentence is essential to its interpretation is not at all the same thing as claiming that regimentation of the sentence into concept-encoding elements is essential to its interpretation.

This slippage, from (i) the innocent claim that the theoretical role of an account of structure at LF (or D-structure) requires it to mesh with an account of semantic competence, to (ii) the claim that robust facts about concepts and their relation to one another drive the need for structural descriptions at this level, is also evident in the following passage:

[W] hat items occur under single nodes in "deep syntax" depends precisely upon meaning; in particular upon what concepts the sentence expresses and how these concepts are related (p. 79).

After granting that the level of representation we are dealing with must somehow capture semantically relevant factors, is anything gained by treating the latter as conceptual factors? The fact that the level of representation we are dealing with must capture semantically salient structure leads us down the road to a robust concept-encoding constraint on constituency only if the task of semantic theory cannot be characterised without appealing to either concepts or hypostasized meanings. And I have already argued in the previous section that it is not the necessary, when theorising about the semantic interpretation of sentences, to make such an appeal. So I hope at the very least to have called into question Stainton's claim to have shown that "the order of explanation [is] precisely the reverse" (p. 79) of that required by the pleonastic theory.

\section{Conceptions and the continuum hypothesis}

Up to this point I have been defending and modifying the pleonastic theory against Stainton's explicit objections. In a more conciliatory mood, I now want to consider two inter- 
esting issues that emerge in Stainton's discussion, though not in the form of direct objections on his part. The first of these concerns his continuum analysis of possession (to be considered in this section; see Stainton, pp. 71-72). The second (to be considered in section five) concerns a further problem about the relation between complex concepts and deeper-than-surface constituency, a problem even Stainton faces.

Stainton suggests - as part of an analysis of where the pleonastic theory supposedly went wrong in its treatment of concept mastery - that instead of seeing concept possession as an all or nothing thing (as would be the case were the pleonastic theory correct), one should see it as a matter of degree. The pleonastic theory's clause for (what it calls) concept possession does for (what Stainton calls) deployment, the tail end of (what Stainton calls) possession. This view of possession as a matter of degree is compelling, and it would be good to accommodate it. The main challenge to doing so turns out to be terminological. Clearly, if "possession' has been reserved for picking out what Stainton calls deployment, we need some other word for the thing that admits of degrees (what Stainton calls possession).

An obvious word to use is 'conception'.9 One's conception of a thing is a function of the beliefs - and perhaps desires - one has concerning it. Two people can share a large number of beliefs about a thing without sharing all their beliefs about that thing. Two people share the same conception of, say, cigarettes, to the extent that they share the same salient beliefs concerning cigarettes. Further, let our own set of beliefs about cigarettes, or else the set of all truths about cigarettes, be used to fix an implicit frame of reference. Then we can also talk of people's having or

${ }^{9}$ I use the term in this way in the final paragraph of the original paper, as does Putnam (1981), pp. 116-117. 
not having a proper conception of cigarettes, or of their having a partial conception of them. What we really mean is that they share more or less the same salient beliefs as us about cigarettes, or else that they do or do not appreciate the more salient facts about cigarettes. ${ }^{10}$

Stainton's continuum analysis of the failings he attributes to the pleonastic theory indicates that he would be in sympathy with the spirit, if not the terminology, of the previous paragraph. But belief in such a continuum needs to be prised apart from an account of mastery which is quite different from that offered in section two above. In implying that a continuum ranges from concept deployment, through concept mastery, to complete knowledge of everything about, say, cigarettes (pp. 72-73), Stainton risks running the account of mastery together with the continuum view in a way which would suggest, misleadingly, that the continuum hypothesis is antithetical to the pleonastic theory. An example will help to see how.

Cigarettes are made of tobacco. Should this widely recognised piece of information be given a privileged status, over and above its being widely recognised, taken for granted in most contexts? The kind of privileged status I have in mind is variously marked using characteristic figures of speech. It is said of someone who lacks this information that they do not know what it is to be a cigarette, or that they have no mastery or grasp of the concept cigarette, that they do not really know what 'cigarette' means, and so on. Another indicator is when a writer says that it is part of the concept cigarette that cigarettes are made of tobacco. What these figures of speech typically prefigure is a refusal to countenance the attribution of genuine ('conceptual' be-

10 One common belief about cigarettes it is well to keep in mind is that they satisfy the predicates such as 'is a cigarette'. 
liefs concerning - in this case - cigarettes to the ignorant party.

One can recognise the coherence of the idea that there is a continuum, and adopt the language of conceptions, without making the following strong mastery claim (where this label is deliberately introduced to distinguish it from the analysis of mastery in terms of understanding, above): that there is some such paradigmatic piece of information about cigarettes (or computers or podiatrists), possession of which is vital to the proper attribution of beliefs concerning cigarettes (or those other objects), in any context. ${ }^{11}$ Though compatible with the continuum hypothesis alone, the pleonastic theory probably cannot sustain endorsement of the strong mastery claim. The strong mastery claim would likely allow the reinstitution of lacks-the-concept inferences, based on lack of mastery rather than lack of possession.

Stainton's own attitude towards the strong mastery claim is ambivalent. On the one hand, he does want to claim that there is a significant point on the continuum somewhere between (what he calls) deployment and total knowledge, and he calls that point the point of mastery, or complete grasp, of the particular concept. He argues that the point is "crucial" (p. 73), since it captures the point at which someone can be said to know what cigarettes are. But on the other hand, he does not want to treat mastery as a prerequisite of belief, holding that one can believe that podiatrists are not dentists without having mastery of the concept podiatrist (p. 73).

But once one has dropped the strong mastery claim, i.e. that aspect of concept mastery which makes it a prerequisite of genuine belief, what point is there to holding on

11 A variation would be to designate a certain ability (say, a recognitional ability, or an inferential ability) as the sine qua non. 
to this notion of mastery at all? The expression, 'knowingwhat-it-is-to-be-an- $X$ ', can be regarded as one in a string of idioms - see above - whose conventional function is to gesture towards some significant piece of information the possession of which is allegedly essential for the correct attribution of beliefs concerning $X$. Since he is not willing to go this far, Stainton is left with a notion (mastery) and a figure of speech ("knowing-what-it-is-to-be-an- $X$ "), neither of which has any manifest philosophical role. Unless, of course, that role comes down to the role played by conceptions, in which case we are reconciled in all but terminology.

I asserted without argument that the continuum view - as expressed in the language of conceptions - is compatible with the pleonastic theory of concepts. The missing reasoning is this. ${ }^{12}$ Suppose it is true that to have any beliefs at all about cigarettes requires having at least three beliefs about cigarettes. In other words, suppose that in order to have any beliefs about cigarettes, one must have a proper conception of cigarettes (where 'having a proper conception' is arbitrarily tied down for simplicity to one's having at least three beliefs). And suppose secondly that having any belief whatsoever about cigarettes requires that one possess the concept cigarette. It follows logically from the second supposition that possessing at least one belief about cigarettes is sufficient for possessing the concept cigarette. This consequence - in effect, the pleonastic theory's clause for concept possession- is quite compatible with the first supposition that beliefs come in clusters of at least three. (The number three is not particularly significant, here, since the reasoning works no matter

12 This is a recapitulation of the reasoning found in the Reply to Objection I of Barber (forthcoming). (I am assuming that having a belief about a cigarette is a less pleonastic way of having a belief involving the concept cigarette.) 
where on the continuum one discerns propriety in a particular conception.)

There can still be evidence that would defeat a prima facie reason to attribute a particular belief about, say, cigarettes to a subject. For example, the implausibility of attributing a wide variety of other salient beliefs about cigarettes to the subject can sometimes work against the original attribution. Call this a lacks-the-conception inference. But a significant feature of this inference is that the source of the defeating evidence lies in the fact that beliefs come in clusters; there is no ghostly entity they fail to possess. Moreover, there is unlikely to be any invariant conception (some particular belief or subset of beliefs about cigarettes) possession of which is in every context essential to the proper attribution of any belief whatsoever about cigarettes.

\section{Skeletal descriptions and complex concepts}

I close with a discussion of a threat to the pleonastic theory connected to Stainton's discussion of involvement. Take the sentence:

Marie kicked John, hard.

Which of the following complex concepts ${ }^{13}$ are involved in the proposition expressed by this sentence?

The concept kick hard

The concept kick John

On intuition alone, both. But the deeper-than-surface representation of the sentence cannot have both 'kick hard' and 'kick John' as constituents. So the appeal to deeper-

13 A complex concept is a concept expressed using at least one space-bar. 
than-surface structure is threatened since constituency at this level cannot be necessary for concept involvement. ${ }^{14}$

The difficulty emerges out of a failure to recognise the shorthand nature of the italicised expressed used to refer to complex concepts. Consider the first of the two concepts above - or rather, consider the way in which it was named. This may be thought of as shorthand for:

The concept someone kicking someone hard

with each 'someone' left unvoiced. Call this latter the skeletal mode of description of the concept (as opposed to the earlier truncated mode). The second concept would be referred to, in skeletal mode, as:

The concept someone kicking John in some way

The way around the objection is to allow that both italicised expressions are components, in some sense, of the sentence (at whatever level of structure).

The sense in which they are components cannot be that they are structural constituents. Instead, we can say that a given complex concept is involved in a given proposition when, and only when, by adding "flesh" to a more detailed skeletal description of the concept one would arrive at a sentence expressing the proposition. (For simple concepts, this is just going to collapse into constituency as before.)

That solves the immediate problem. But the introduction of skeletal descriptions can be used to make a further point. It does not really matter if we lack an exact criterion for whether particular combinations of surface elements of a given sentence "belong together" in a way which makes them expressive of individual (albeit complex) concepts. The general drift of the pleonastic theory is that concept-

14 Notice how Stainton's claim, that the point of constituency at deeper-than-surface structure is to encode or express individual concepts, is likewise threatened here. 
talk is a lapse, an indulgence, so discovering that it was also lacking in precision would be discovering just one more hole in the hull. And there certainly does seem to be considerable flexibility — read: imprecision — in the matter of whether or not we can bring together a given pair of phonologically distinguishable elements in any given sentence and treat them as constitutive of a concept.

For example, even the elements 'John' and 'hard' could be seen as "belonging together" in the earlier sentence. The name:

The concept John hard

is uncomfortable. But this could be seen as a failed attempt to truncate:

The concept doing something to John, hard.

In fact, with some ingenuity and by allowing skeletal descriptions, one can combine just about any pair of surface elements to give a concept. And extremely little philosophical or linguistic interest seems to attach to the project of charting the borderline separating permissible from impermissible truncations of skeletal modes of description. Which is to say, extremely little philosophical or linguistic interest seems to attach to the project of isolating a precise guide to when a given complex concept (truncatedly described) is involved in a given proposition. ${ }^{15}$

\section{REFERENCES}

Barber, Alex (forthcoming) "The Pleonasticity of Talk About Concepts", Philosophical Studies.

15 Thanks to Jesús Aguilar and a referee for their helpful suggestions, and to the former for translating the abstract. 
Chomsky, Noam, 1995, "Language and Nature", Mind, 104, pp. 1-61.

Davidson, Donald, 1984, "On Saying That" as reprinted in his Essays on Truth and Interpretation, Clarendon, Oxford.

Frege, Gottlob, 1891, "On Function and Concept", in Max Black and Peter Geach (eds.), Translations From the Philosophical Writings of Gottlob Frege, 3rd ed., Blackwell, Oxford, 1980.

— , 1892, "On Sense and Reference", in Max Black and Peter Geach (eds.), Translations From the Philosophical Writings of Gottlob Frege, 3rd ed., Blackwell, Oxford, 1980).

Mcdowell, John, 1977, "On the Sense and Reference of a Proper Name", Mind, 86, pp. 159-185.

Putnam, Hilary, 1981, Reason, Truth, and History, Cambridge University Press, Cambridge (GB).

Stainton, Robert J., 1996, "The Deflation of Belief Contents" Crítica, vol. XXVIII, no. 84, December 1996, pp. 63-82.

Recibido: 9 de diciembre de 1997 


\section{SUMMARY}

La teoría pleonástica de los conceptos continúa siendo viable a pesar de las recientes críticas que ha recibido por parte de Robert J. Stainton (Critica, diciembre 1996). En particular el dominio de un concepto puede considerarse como la comprensión de un término que expresa tal concepto. Lo cual en ningún sentido amenaza el carácter deflacionario de la teoría pleonástica, en la medida en que tal comprensión sea vista de una manera apropiada. Más aún, recurrir a la noción de un constituyente estructural a un nivel sintáctico profundo como el que vemos en lingüística contemporánea, no genera necesariamente una interpretación robusta del lenguaje de los conceptos. 